\title{
Environmental Factors of College Students' Outdoor Sports Participation from the Perspective of Ecosystem Theory
}

\author{
Zheng Zou ${ }^{1}$ \\ ${ }^{1}$ Department of Foundation, Shenyang Polytechnic College, Liaoning, 110045, China
}

\begin{abstract}
:
With the rapid development of urbanization and industrialization, there are a series of ecological environment problems. Ecological environment is one of the basic environmental elements for human survival, and physical exercise also needs to be carried out in a certain appropriate environment. In particular, outdoor physical exercise, more need to have a good ecological environment as a guarantee. This paper discusses the feasibility of outdoor sports as a means of education from the perspectives of ecosystem and behavior. In terms of theoretical analysis, on the basis of fully understanding the research status of outdoor sports at home and abroad, this paper summarizes the concepts and theories related to outdoor sports, and makes an in-depth discussion on the content of outdoor sports. This paper makes a theoretical analysis on the development of outdoor sports in Colleges and universities. At the same time, this paper discusses that carrying out outdoor sports among college students is in line with the needs of cultivating all-round development people in higher physical education. This paper holds that outdoor sports are closely related to environmental factors. Improving the ecological environment is conducive to the cultivation of a good and positive way of life for college students of physical education..
\end{abstract}

Keywords: Ecosystem, ecological theory, environmental protection, sports participation

\section{AIMS AND BACKGROUND}

The research significance of air quality and exercise is also very important in life. As we all know, the atmosphere is a necessary condition for the survival of all organisms on the earth. However, with the rapid development of industry in recent years, the rapid increase of urban population and the rapid growth of energy and fuel use, the atmospheric environmental quality in many urban areas is gradually deteriorating[1-2]. Air quality 
pollution not only poses a threat to human living environment, but also seriously affects human physical and mental health. In the current social situation, more and more people have joined the sports team without hesitation in order to improve their health and quality of life. Physical exercise activities need to be carried out in a suitable natural environment. The environment is the material basis for human beings and all kinds of organisms to survive. Organisms have a certain tolerance threshold to their environment. As long as the tolerance range exists in the threshold range, the life activities of human beings and all kinds of organisms can be continued. In other words, if the human environment is polluted and leads to abnormal environmental rhythm, the abnormal environmental rhythm will disturb and hinder the inherent rhythm of human life, thus breaking the original inherent rhythm and causing the disorder of human life rhythm. So it can be seen that the research on environment and physical exercise has certain scientific and practical significance.

\section{EXPERIMENTAL RESEARCH OBJECTS}

The research object of this paper is the outdoor physical exercise crowd and air quality in Y District.

The subjects were 296 outdoor exercisers in Pingyang square, Gulou square and school playground of Y District. There were 129 males and 167 females; There were 80 people aged 21-30, 28 people aged 31-40, 40 people aged 41-50, 70 people aged 51-60 and 78 people aged over 60; Among them, there are 65 people in the learning stage, 84 people in the normal working stage and 147 people in the retired and other groups.

The research content of air quality status is air quality index, which adopts the air quality index and primary pollutants of Y District in 2019[3-5]. Including: PM2.5, PM10, SO2 index, NOx index, inhalable particulate matter. The data is from the Ministry of environmental protection of the people's Republic of China.

\section{RESEARCH METHOD}

\section{Questionnaire survey method}

The main contents of the questionnaire in this paper mainly include: first, the basic situation of the individual, ordinary outdoor exercise situation; Second, personal awareness of air quality.

In order to ensure the reliability of the questionnaire, the first part of the population to test the distribution of small samples, according to the answers to the reliability and validity test, in addition to multiple-choice questions. The results are shown in Table 1 


\begin{tabular}{cc}
\multicolumn{2}{c}{ Table 1. Reliability statistics of questionnaire } \\
\hline Cronbach's Alpha & Number of items \\
\hline 0.731 & 13
\end{tabular}

SPSS17.0 software was used to analyze the reliability of the data, and the homogeneity reliability a was 0.7314-5. Generally, the required range of Cronbach's Alpha is 0.6-0.8, while the reliability coefficient a of this questionnaire is 0.731 , which is within the required range, so this questionnaire has good reliability. 320 questionnaires were distributed to outdoor exercisers in Y District, and 302 questionnaires were collected, among which 296 were effective, with an effective rate of $92.5 \%[6]$.

2.Mathematical statistics

After sorting out the questionnaire, using SPSS17.0 for mathematical statistics and analysis, the data supporting the paper are obtained and analyzed.

\section{Tracking statistics}

The air quality index of Y District was tracked for one year, and the daily and hourly air quality index and primary pollutants in 2014 were collected (the data came from the Ministry of environmental protection of the people's Republic of China). The number of days of each air quality level in a year is calculated by using the arithmetic method, and the number of days of the primary pollutants in a year is also counted, and then the air quality status and the types of primary pollutants in Y District are analyzed.

4. Interview method

By interviewing the relevant professors in the school of urban and Environmental Sciences of Shanxi Normal University, we can understand the air quality situation and related research in Y District, and obtain some opinions and suggestions on this paper. Through interviews with the relevant staff of Y District Environmental Protection Bureau, the relevant contents were understood.

\section{Literature method}

By consulting the books related to this study, the theoretical understanding of air quality and the causes of pollution is deepened, which provides a sufficient theoretical basis for the writing of this paper. Through the Internet retrieval, using Tsinghua Tongfang database computer literature retrieval, access to the full text database of Chinese academic journals, we have a deeper understanding of the impact of air quality on exercisers, which provides a strong theoretical support for the theoretical analysis and collation of this study.

\section{RESULTS AND DISCUSSION}


1.analysis on the current situation of outdoor physical exercise crowd in y district

It can be seen from table 2 that $26.2 \%$ of the people in the learning stage take outdoor physical exercise 1-2 times a week, 53.8\% take outdoor physical exercise 3-4 times a week, and $20 \%$ take outdoor physical exercise more than 5 times a week. In the normal working stage, $4.8 \%$ of the people took outdoor physical exercise 1-2 times a week, $70.2 \%$ took outdoor physical exercise 3-4 times a week, and $25.0 \%$ took outdoor physical exercise more than 5 times a week. $2.0 \%$ of the retired and other people took outdoor physical exercise 1-2 times a week, $21.8 \%$ took outdoor physical exercise 3-4 times a week, and $76.2 \%$ took outdoor physical exercise more than 5 times a week. It can be seen that there are some differences in the number of weekly physical exercise in different stages of the population. The proportion of people who exercise 1-2 times a week belongs to the learning stage is the highest, the proportion of people who exercise 3-4 times a week belongs to the normal working stage is the highest, and the proportion of people who exercise more than 5 times a week belongs to the retired and other groups is the highest. It also shows that the older the people who exercise, the more free time they have, the more times they exercise every week[7-9].

Table 2. Weekly exercise frequency of outdoor exercise crowd

\begin{tabular}{cccc}
\hline Crowd & 1-2 times & 3-4 times & More than 5 times \\
\hline People in learning stage & $26.2 \%$ & $53.8 \%$ & $20.0 \%$ \\
Normal working population & $4.8 \%$ & $70.2 \%$ & $25.0 \%$ \\
Retirees and others & $2.0 \%$ & $21.8 \%$ & $76.2 \%$ \\
\hline
\end{tabular}

Table 3. Analysis on the situation of exercise places of outdoor physical exercise crowd

\begin{tabular}{ccccc}
\hline Exercise place & Frequency & Percentage & $\begin{array}{c}\text { Effective } \\
\text { percentage }\end{array}$ & $\begin{array}{c}\text { Cumulative } \\
\text { percentage }\end{array}$ \\
\hline School playground & 66 & 22.3 & 22.3 & 22.3 \\
Nearby park & 12 & 4.1 & 4.1 & 26.4 \\
square & 136 & 45.9 & 45.9 & 72.3 \\
Beside the road and street & 11 & 3.7 & 3.7 & 76 \\
Not fixed & 71 & 24 & 24 & 100 \\
\hline
\end{tabular}

It can be seen from table 3 that square is the primary place for outdoor physical exercise in Y District, accounting for $45.9 \%$, school playground for $22.3 \%$, nearby park for $4.1 \%$, highway and roadside for $3.7 \%$, and irregular proportion for $24 \%$. This may be because the square is a public place with good geographical location and large area, which can 
accommodate a lot of people to exercise. At the same time, there are many exercise items in the square, rich in content, and there are many choices. People do not need to take any factors into account when they exercise. As long as they are willing, they can join any item for exercise. In addition, it may be that an orderly management and organization form has been formed in the square for many years, and some organizations or teams have a relatively stable daily exercise crowd. They will provide you with free audio and suitable music, and teach you some exercise programs for free or at low cost, thus providing more convenience for the exercise crowd. Most of the exercisers in the school playground are students who exercise freely, and the school playground is the safest and most convenient place for them.

2.analysis of air quality and air pollution types in y district

Before the 1980s, Linfen once enjoyed the reputation of "flower and fruit city". However, due to the rich coal resources, the rapid development mode has rapidly changed the beautiful face of Linfen City. With the development of heavy industry, the environmental problems of Linfen City are getting worse and worse, until it has become the first pollution city in China, even in the world. The air quality index is divided into six levels according to the level. Each level has its corresponding color, corresponding health impact and recommended measures. After the mid-1990s, the air quality of Y District was mainly affected by sulfur dioxide, nitrogen oxides and particulate matter[10]. During this period, the total amount of waste gas emissions increased continuously, but the growth rate showed a downward trend. During 1985-2000, the concentration of sulfur dioxide showed an increasing trend, the level of nitrogen oxides remained stable, and the particulate matter showed a downward trend. Overall, the air quality of Y District is gradually improving.

Since 2012, China added PM2.5 into the urban air quality evaluation system, PM2.5 has emerged as the most harmful primary pollutant in various cities. According to the monitoring data in 2014, the main types of air pollutants in Y District are PM2.5, PM10, sulfur dioxide, carbon monoxide, nitrogen dioxide and ozone. Among them, PM2.5, PM10 and sulfur dioxide as the primary pollutants appeared more frequently than carbon monoxide, nitrogen dioxide and ozone.

3.cognition of outdoor exercisers on air quality in y district

According to existing studies, there is a significant correlation between air pollution and human health, air pollution has a negative impact on human health. Meanwhile, the health production function is used to analyze the extent of the city's air pollution affecting human health. The study shows that air pollution has negative effects on human health, and this effect is the main cause of incidence rate of diseases. In addition, epidemiological studies in Europe and America show that the incidence rate and mortality of asthma in hospitals will increase as the concentration of particulate matter in the atmosphere increases. As can be 
seen from table 4, the understanding of air pollutants and health of different exercise groups is not high as a whole, and most people only know a little. $75.4 \%$ of them are in the study stage, $67.9 \%$ are in the normal working stage, and $60.8 \%$ are retired and other groups. This shows that the awareness of air pollutants and health is not high enough, and the understanding of this aspect is relatively low.

Table 4. Understanding of air pollutants on health hazards of outdoor physical exercise crowd

\begin{tabular}{cccc}
\hline Crowd & Know & $\begin{array}{c}\text { Has some } \\
\text { knowledge of }\end{array}$ & $\begin{array}{c}\text { Have no idea } \\
\text { at all }\end{array}$ \\
\hline People in learning stage & $18.00 \%$ & $75.40 \%$ & $6.60 \%$ \\
Normal working population & $14.30 \%$ & $67.90 \%$ & $17.90 \%$ \\
Retirees and others & $7.70 \%$ & $60.80 \%$ & $31.50 \%$ \\
\hline
\end{tabular}

As can be seen from Figure 1, Y District outdoor sports crowd's understanding of the source of air pollutants is as follows: the first is automobile exhaust, accounting for $24.8 \%$; the second is coal-fired heating, accounting for $22.6 \%$; the third is domestic waste, accounting for $21.2 \%$; factory pollution, accounting for $18.8 \%$; and the last is construction site, accounting for $12.7 \%$. It shows that the outdoor exercisers in Y District have realized that automobile exhaust has become a major aspect of air quality, followed by coal-fired heating in winter. Although now Y District heating work has become collective heating, compared with the past, pollution is much less. However, the amount of coal consumed by collective heating is still a huge number. The pollutants emitted by coal-fired heating in winter have a serious impact on the air quality of Y District. The smog is diffuse, the air visibility is low, the smell is bad and pungent, leading to people's poor breathing and throat. It can be seen that people's strongest feelings about air pollution are car exhaust and coal-fired heating.

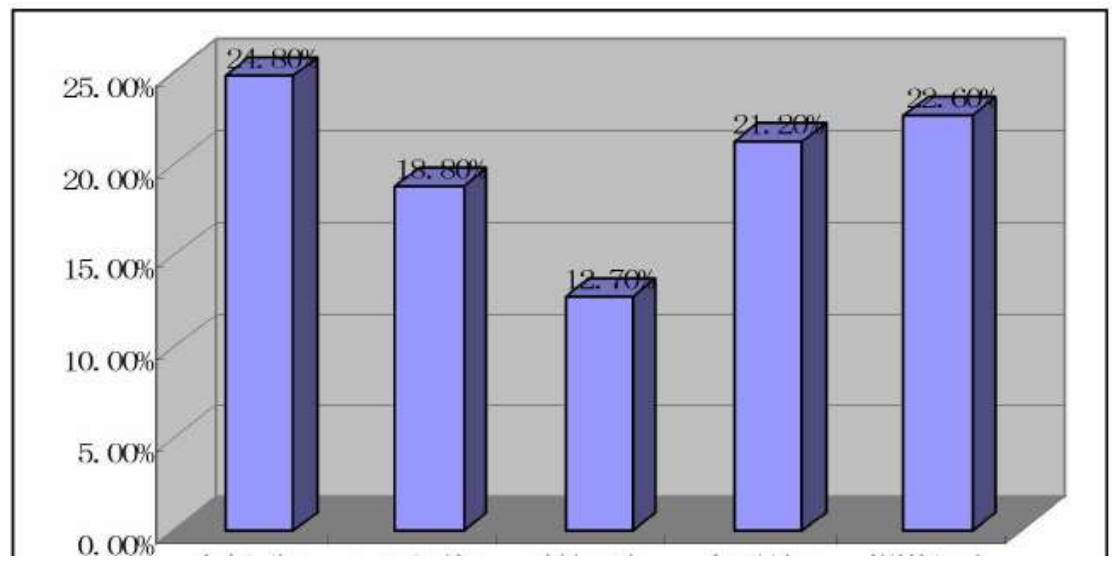


Fig. 1. The cognition of outdoor physical exercise crowd to the source of air pollution

Chen Xiaoping, a human movement expert at Tsinghua University, said: in foggy weather, all sports are not suitable. Li Jing, director of internal medicine of Beijing Sports hospital, said: in foggy weather, susceptible people (children, the elderly and patients with heart and respiratory diseases) are not suitable for sports. They should try to reduce going out. If they want to go out, it is best to choose the time from 10 am to $3 \mathrm{pm}$ to avoid going out in the morning and evening. Qu Jiuhui, academician of the Chinese Academy of engineering and former director of the ecological environment research center of the Chinese Academy of Sciences, clearly stated that "the movement of fog and thunder weather is not good".

\section{PROPOSAL}

In 2013, the Institute of environmental science of Renmin University of China and other institutions put forward that only $10.67 \%$ of the cities in China have excellent air quality status, $75.8 \%$ have poor air quality status, and $13.52 \%$ have extremely poor air quality status. China's environmental governance is obviously lagging behind. Linfen, as a big energy city, has inevitably caused pollution and damage to the atmospheric environment in the rapid economic development. Although the pollution situation has gradually improved since 2006, the pollution problem has a long way to go, and more strict and lasting governance is needed.

Outdoor physical exercise in densely populated areas such as the central square and both sides of the street, and in areas with heavy traffic, will inadvertently become a "vacuum cleaner" of urban atmospheric environment, which will have a great negative impact on the health of exercisers, especially on sensitive people. In order to achieve better exercise effect, outdoor physical exercise crowd should try to avoid crowded areas of people and vehicles in downtown areas with crowded living environment, trunk lines with heavy traffic, and urban squares, and try to choose venues with fresh air quality, more green plants or far away from the above places. For Y District, Binhe Park and Gucheng Park are good exercise venues.

The results show that the way to understand the air quality of outdoor sports people is limited, and it is far from enough to understand the air quality only through television media. Linfen City outdoor physical exercise crowd on the understanding of air pollutants and health is not high as a whole, so we should through a variety of ways to promote air quality related content, let people know more about the importance of air quality, more about the harm of air pollution to people. 


\section{CONCLUSIONS}

This paper mainly through the understanding of Y District outdoor physical exercise crowd's exercise situation, Y District's air quality situation, combined with outdoor physical exercise and air quality, to investigate the outdoor physical exercise crowd's cognition of air quality. Combined with the air quality and the effect of exercise, it points out the misunderstanding of outdoor physical exercise crowd. In view of the misunderstanding of exercise, this paper puts forward some reasonable suggestions from the aspects of improving air quality, scientifically selecting exercise place and time, publicizing knowledge by media, and guiding exercise crowd. The ultimate goal is to make the outdoor physical exercise crowd in Y District more scientific and healthy, and truly realize the meaning of life lies in sports.

\section{REFERENCES}

1. A. G. M. MONIRUL, K. ALAM, S. MUSHTAQ et al.: Vulnerability to Climatic Change in Riparian Char and River-Bank Households in Bangladesh: Implication for Policy, Livelihoods and Social Development. Ecol Indic, 72, 23 (2017).

2. S. E. LEBEDKOVA, V. V. BYSTRYKH, O. A. NAUMENKO, E. GIU: Role of Environmental Factors of an Industrial City in the Etiology of Cardiovascular Diseases in Children. Guiana Sani J, 27 (6), 33 (2013).

3. P. M. MANNUCCI: Airborne Pollution and Cardiovascular Disease: Burden and Causes of an Epidemic. Europe Heart J, 34 (17), 51 (2013).

4. H. DUZEN: Investigation of Heavy Metal Contamination of Drinking Water in the Towns of Muradiye and Caldiran (Van, Turkey). J Environ Protec Ecol, 18 (3), 913 (2017).

5. L. R. POPESCU, M. IORDACHE, L. F. PASCU, E.-M. UNGUREANU, G.-O.BUICA: Applications of the Mathematical Model ANOVA in the Area of an Industrial Platform for Assessment of Groundwater Quality. J Environ Prot Ecol, 17 (1), 33 (2016).

6. M. V. RUBY, A. DAVIS, T. E. LINK et al.: Development of an in-vitro Screening-Test to Evaluate the in-vivo Bioaccessibility of Ingested Mine-waste Lead. Environ Sci Technol, 27 (13), 2870 (1993).

7. L. A. BRANDT, P. R. BUTLER, S. D. HANDLER et al.: Integrating Science and Management to Assess Forest Ecosystem Vulnerability to Climate Change. J For, 115 (3), 212 (2017).

8. Z. DESMIT, A. E. ELHABASHY, L. J. WELLS et al.: An Approach to Cyber-physical 
Vulnerability Assessment for Intelligent Manufacturing Systems. J Manuf Syst, 43 (2), 339 (2017).

9. S. TSIARAS, T. SAMARA, I. SPANOS: Exploring Linkages among Land Use/Land Cover Change, Ecological Footprint and Sustainable Development. J Environ Protec Ecol, 18 (3), 1037 (2017).

10. A. KRIEG: Externalizing the Burden of War: the Obama Doctrine and Us Foreign Policy in the Middle East. Int Aff, 92 (1), 97 (2016). 